\title{
Formação em saúde e micropolítica: sobre conceitos-ferramentas na prática de ensinar
}

Ana Lúcia Abrahão(a) Emerson Elias Merhy ${ }^{(b)}$

Abrahão AL, Merhy EE. Healthcare training and micropolitics: concept tools in teaching practices. Interface (Botucatu). 2014; 18(49):313-24.

Changes in health education over recent decades have been on the political agenda of the Brazilian government, in the fields of methodology and pedagogy, with projects for curriculum restructuring so as to move closer to healthcare services. Healthcare training is examined in this article starting from some concept tools, with linkage to four tensions present in this area: training as a betterment movement; training as a field of living work; training as experience; and training as creation. The purpose of this study was to examine the tensions presented, starting from theoretical meeting points, aligned with production of conceptual tools with the power to install new practices in healthcare education. The analysis indicates the creative potential that micropolitics has within the training process. As the main element, it expands experience and the capacity to discern other ingredients and other territories within pedagogical action.

Keywords: Teaching. Micropolitics. Healthcare education.
As mudanças na formação em saúde, nas últimas décadas, têm estado na agenda da política do Estado brasileiro, no campo metodológico e pedagógico, com propostas de reestruturação dos currículos e maior aproximação com os serviços. A formação no campo da saúde é trabalhada neste artigo a partir de alguns conceitosferramentas, articulados a quatro tensões presentes neste campo: formação como movimento de produzir-se; formação como território do trabalho vivo; formação como experimentar e formação como criação. O propósito deste estudo consiste em ponderar as tensões apresentadas a partir dos encontros teóricos, alinhados à produção de ferramentas conceituais com potência para instalar novos modos de exercício na formação em saúde. A análise assinala o potencial criativo, exercido no micropolítico no ato da formação. Como elemento principal, amplia a experiência e a capacidade de enxergar outros ingredientes e outros territórios no agir pedagógico.

Palavras-chave: Ensino. Micropolítica. Formação em saúde.
(a) Escola de Enfermagem, Universidade Federal Fluminense. Rua Dr. Celestino, 74. Niterói RJ, Brasil. 24240-660 ana.abrahao@ pesquisador.cnpq.br (b) Faculdade de Medicina, Campus Macaé, Universidade Federal do Rio de Janeiro. Rio de Janeiro, RJ, Brasil. emerson.merhy@ gmail.com




\section{Introdução}

O campo da formação em saúde, ao longo das duas últimas décadas, vem sendo desenhado e recortado por iniciativas de ordem prática, política e pedagógica que traçam diferentes formas e modos de como se ensina e se aprende a ser profissional.

Costuma-se pensar e entender a formação por uma dada ciência, técnica e racionalista, que aplica diversas tecnologias pedagógicas aos alunos, sob um ponto de vista que opera a partir de um saber cientificamente comprovado. Um produto pronto para ser consumido e reproduzido. Um aprendizado que estimula muito pouco o exercício de autonomia e de crítica, pois parte do princípio de que expor o aluno ao conteúdo é suficiente para a formação. Uma ciência aplicada que, fracionadamente, vai sendo exposta e é assumida como centro do aprendizado, com pouca margem para outros tipos de conexões existenciais e de produção de conhecimento, durante o processo de formação. Ou seja, uma baixa capacidade de produzir arranjos pedagógicos que apresentem formas diferentes de aprender e que provoquem outras possibilidades na identificação dos distintos modos de existir que há no mundo. Formas de ensinar e aprender que convivem com sujeitos e os seus modos de vida singulares, que demandam uma atenção tão singular, quanto.

A formação pode ser reconhecida a partir de outro lugar, sob outra perspectiva, que convida o aluno a experimentar, a criticar, a participar da experiência de ensinar e aprender. "A experiência como aquilo que nos passa, o que nos acontece, o que nos toca. Não o que se passa, não o que acontece, ou o que toca. A cada dia se passam muitas coisas, porém, ao mesmo tempo, quase nada nos acontece"1 (p. 22). Há aqui uma diferença entre aquilo que vivenciamos e se torna uma experiência em nós, e o que vivenciamos e não nos afeta de modo a exigir novas significações. Há distinção entre ser algo que encontra sentido e nos toca, como um acontecimento(c), e aquilo que não nos traz para novos campos de sentidos.

Estamos pensando em uma prática pedagógica que inclua outras conexões possíveis para a formação, que seja um acontecimento. Ou seja, que produza abalos no campo dos sentidos, na efetuação daquilo que passa e toca no cotidiano da formação, em que os sujeitos (professor-aluno-usuário-profissional) envolvidos busquem novos significados para dar conta do que acontece a eles. "O acontecimento obriga que possibilidades que julgávamos impossíveis, que excediam nosso sentido do provável sejam [possam ser] reconhecidas"2 (p. 5).

Pensamos em uma formação que permita a produção centrada na articulação de diferentes saberes, conhecimentos e aprendizados, e no território da vivência/ experiência do aluno, partindo desse como sujeito da problematização da própria formação. Outro modo de produção que inclua outras possibilidades para além da inculcação de um saber científico aplicado.

Assim, chegamos diante de, pelo menos, dois aspectos de ensinar e aprender, presentes no campo da formação. Um vinculado à certeza de que, expondo os alunos a um saber cientifico, haverá a formação, o aprender. O segundo relacionado a uma prática pedagógica que promove a emergência de novos saberes e suas articulações, os quais o aluno-professor experimenta durante a ação problematizadora.

No campo da formação em saúde, reconhecemos a convivência destes dois movimentos atuando ao mesmo tempo e em disputa. Uma perspectiva que coloca a saúde como resultado do saber científico, da ciência aplicada, com a utilização de estratégias de normatização da vida do outro; e outra que deposita, na prática em saúde, as possibilidades de se alinharem os diferentes modos de produção do (c) Em Deleuze ${ }^{3}, \mathrm{o}$ acontecimento é um conceito paradoxal, não segue o bom senso (que fecha o sentido) e nem o senso comum (que dá identidade fixa).

Acontecimento é o local de troca entre o estado de coisas e o improvável, o sujeito neste instante é tomado, buscando produzir algum tipo de sentido na efetuação. É exatamente por não ter sentido em meio àquilo que já existe que o acontecimento obriga o sentido, fazendo com que o sujeito busque novos significados para dar conta do que acontece a ele. 
(d) Este estudo compreende o território para além do geográfico, delimitado fisicamente, como o que ultrapassa as linhas, como sinônimo de articulação com outros modos de existência. está dado, ao contrário, stá em construção. "O está em construção. “O território é sinônimo de apropriação e de subjetivação" ${ }^{5}$ (p. 323). viver, singulares, e que constituem as maneiras de andar a vida, nos processos de encontros micropolíticos entre trabalhadores e usuários ${ }^{4}$.

Desenhos que se centram no saber que a prática em saúde é resultado da lógica cientificista, classificatória, protocolar, circunscrita em uma produção única do sofrimento como doença, em que os distintos modos de sofrimento e de existir estão ausentes, juntamente com a produção de territórios ${ }^{(d)}$ identitários do usuário.

O ensinar centrado no saber científico, de modo exclusivo, produz processos em que o complexo mundo do usuário e daquilo que ele busca nos serviços de saúde, ganha pouca visibilidade e pertinência. Com muita frequência, reconhecemos os vestígios desta aprendizagem nos serviços, nas produções de barreiras ao acesso dos usuários ao cuidado integral, bem como na centralidade que a doença ocupa neste processo, com a interdição da aparição dos muitos sujeitos que há aí em potência, no plano da vida do usuário.

Os vários territórios, tomados como campo de experiência prática, abrem-se para a combinação de diferentes conexões como elemento para a formação. Um processo que, ao articular a prática do trabalho em saúde, remete ao desafio de construção de artifícios pedagógicos que reconheça a possibilidade das várias existências presentes nesse plano de produção, o qual opera no entre alunoprofessor-usuário-profissional de saúde.

O desafio se coloca como pergunta: como reconhecer nesse processo de formação, no campo da saúde, ferramentas que, combinadas, transitem pela multiplicidade e extensividade do campo de forças e dos fluxos que interagem nesse plano? Multiplicidade dada a partir do emprego das ferramentas pedagógicas e do cuidado em ato, e que nos convoca, a cada momento, a uma nova ação, principalmente quando nos deparamos com modos de agir completamente diferentes ante o mesmo usuário.

E extensividade por esta ação se ampliar e ir em diferentes direções, não havendo via única. Alguns autores, do campo da Educação Permanente em Saúde, vêm demonstrando a potência de transitar na interface e nos limites disciplinares e construir espaços de aprendizado em outra perspectiva.

Essa perspectiva reconhece que a formação em saúde transita de forma transversal nos territórios disciplinares, produzindo conhecimento e revelando novas aproximações sobre a realidade. As fronteiras se abrem e permitem a aproximação pelo entre, pelos poros ${ }^{6}$. Este movimento de constituição transversal para a compreensão do real incorpora diferentes direções em meio às várias disciplinas, que podem vir a promover processos coletivos de produção 7 .

A transversalidade incorpora um intenso movimento entre os territórios das disciplinas. Transversalidade em oposição a uma verticalidade e a uma horizontalidade, que constituem os processos de subjetivação. Processos que mobilizam ações, gestos, afetos e afecções, conhecimentos e verdades que conjugam a nossa existência. Este movimento aporta a potência de mobilizar forças, grupos e sujeitos ${ }^{8}$. Uma possibilidade de aluno-professor ter acesso diferenciado às áreas de conhecimento, como uma produção singular, que parte da multiplicidade e não obedece à hierarquia das disciplinas. A sua relação com os saberes é oblíqua e o resultado é inesperado. Com este fim, o processo de formação gera a possibilidade de inaugurar vínculos e trabalhar com ações estabelecidas a partir do encontro entre usuários-profissionais-alunos-professores.

Reconhecemos a importância da utilização de conceitos-ferramentas trataremos disso adiante - que possam configurar como elementos que nos levem a pensar e a produzir, em ato, arranjos que ativem a mudança no ensinar, aprender na saúde, a partir do reconhecimento de que a formação encontra-se em um plano poroso de existência. 
O debate, escolhido para este trabalho, adota as disputas no campo da formação em saúde e se propõe a operá-las a partir de alguns conceitos-ferramentas, tendo como contexto quatro tensões que reconhecemos estarem presentes neste campo: formação como experimentar; formação como um movimento de produzir-se; formação como território do trabalho vivo em ato; e formação como criação.

\section{Operando nas tensões da formação em saúde a partir de conceito-ferramenta}

A escolha de trabalhar as tensões da formação - como um movimento de produzir-se; como território do trabalho vivo em ato; como experimentar; e como criação - deu-se pelo fato de identificarmos as tensões constitutivas que se abrem às potências e disputas de modos de ensinar e aprender, que são geradas no campo da formação, e, consequentemente, concentram muitos conceitos.

Entendemos que "todo conceito remete a um problema, problemas sem os quais não teria sentido, e que só podem ser isolados ou compreendidos na medida de sua solução [...]"9 (p. 27-8). Ao trabalharmos as tensões, estamos agindo sobre os conceitos, sobre o campo de experiência que se coloca como um problema do experimentar na existência. Uma ferramenta que age sobre as verdades da vida, uma ferramenta para viver o conceito, como vida.

No sentido de compreender conceito como uma ferramenta, tomaremos o acolhimento, como exemplo. Se olharmos o acolhimento como um conceito de representação da vida, facilmente chegaremos ao consenso de que, na prática, precisamos ter escuta durante o atendimento ao usuário, abrir espaço na agenda dos serviços, construir com a equipe o entendimento de que é preciso "acolher", não mandar o usuário de volta sem antes ouvir e conduzir a queixa. O conceito acolhimento como representação passa, então, a figurar nos serviços como aquele espaço para o qual o usuário é encaminhado quando chega e não há vaga para ser atendido. Reconhecemos ser uma mudança importante no contexto hegemônico da organização dos serviços, mas que mantém a centralidade na doença.

Tomar acolhimento como conceito-ferramenta nos remete a outra ordem de mudança, que opera para dentro da equipe, provoca e desperta alterações no corpo e no enunciado do usuário e profissional de saúde, que representa para além da construção de protocolo de risco; passa a incluir na sua ação o que toca o usuário e o que toca o profissional. O acolhimento adquire a dimensão da nossa própria ação trabalhador-usuário, existe, portanto, como acontecimento, e não como representação.

Acolher se transforma em ferramenta e atua sobre a escuta, não mais seletiva e classificatória, mas no que opera no ato do encontro, no entre, podendo agir na direção de um escutar incluindo, como um ir ao ato da escuta. O acolhimento como processo de encontro intercessor passa a ser o local de troca entre o estado de coisas e aquilo de que temos dúvidas, pelo acontecimento micropolítico que aí age. Isso pode implicar a busca da produção de algum outro tipo de sentido na efetuação. Operar acolhimento como ferramenta é fazer uso dos novos significados para dar conta do que acontece.

Assim, viver o conceito passa a se revelar como um problema do experimentar, dos e nos acontecimentos vividos, aquilo que nos passa, o que nos acontece, o que nos toca. Constituindo-se como o local de troca entre o estado de coisas e o improvável, o inusitado que está presente. Entretanto, a produção de sentido para o sujeito da ação, que se coloca no ato do experimentar, é fundamental.

Viver o conceito como ferramenta na produção de vida remete à produção de agenciamentos. Agenciamento ${ }^{10}$ como a composição de elementos que se fazem presentes durante a relação - sejam eles os elementos em que ordem for: objetiva, subjetiva, sentimental, sensorial etc. Elementos heterogêneos entre si, que incorporam a expressão de vários conteúdos.

Trabalhar conceito como vida agencia os elementos que se fazem presentes na relação usuário-aluno-professor-profissional, em um movimento que vai alargando as possibilidades do experimentar em diferentes campos de problemas.

Os elementos heterogêneos, presentes no agenciamento, trazem para a cena as disputas dos mecanismos de subjetivação, existentes no campo da formação. Nesse cenário, é possível identificar uma produção subjetiva que se cristaliza em processos institucionalizados de ensinar, como aulas 
centradas no saber docente, versus outros modos de subjetivação com uma maior margem à entrada de diversos modos de existência, como aulas-experimentos que agreguem outras possibilidades de problematizações e saberes.

$O$ agenciamento funciona como um grande plano em que elementos heterogêneos se apresentam e, por isso mesmo, se confunde durante a relação. Quando estamos operando o conceito, seja como ferramenta ou como representação, os agenciamentos estão presentes. O interessante é perceber que ali se encontra cravada a disputa de modos de subjetivação, que adquirem sentido ou não nos problemas da vida.

Modos de subjetivação como

[...] o espaço de relação que se produz no encontro de "sujeitos", isto é, nas suas intercessões, e que é um produto que existe para os "dois" em ato, não tendo existência sem este momento em processo, e no qual os "inter" se colocam como instituintes em busca de um processo de instituição muito próprio, deste sujeito coletivo novo que se formou. ${ }^{11}$ (p. 318)

Intercessão, em ato, no momento da produção usuário-aluno-professorprofissional. Um inter que produz intervenção na arte da formação ${ }^{11}$. Novos sentidos para o saber, abertos para entrada de outros saberes, para outros regimes de verdade que encontram lugar durante o processo de formação.

Nesta ordem de variações, os conceitos-ferramentas, em seu devir ${ }^{(e)}$, se

de Deleuze e Guattari ${ }^{9}$ que remete ao desejo, a força e a potência presente e que não é imitada e não está enquadrada. Não é generalizável é, antes de tudo, fenômenos, evolução de mudança. inscrevem como potência de produção de conexões e remetem a outros conceitos, produzindo ecos e ressonâncias. Com esta imagem se desenha uma provocação, operando na construção de uma formação em saúde mais próxima das questões do viver. Produzir, no encontro usuário-profissional de saúde-aluno-professor, intercessões com redimensionamento e alargamento do modo de andar a vida e do cuidar de $\mathrm{si}^{12}$, com o exercício de conceitos-ferramentas no ato da formação.

\section{Formação como experimentação}

A experiência como elemento dinamizador da formação implica colocar-se à disposição do exercício de apreender com e no mundo do trabalho, enquanto um campo essencialmente micropolítico. A formação nos convoca a experimentar durante o cuidar, durante o ato do trabalho; despertar sensações e afetos produzindo-se no cuidado.

O sentido do cuidar implica processos que se tornem imanentes e referentes às múltiplas possibilidades relativas ao encontro. Imanentes, pois têm como ponto de partida o próprio encontro; múltiplos, pelas diferentes possibilidades de, no mesmo encontro, identificarmos uma multidão de encontros, que passa pela troca de olhar, pela construção e produção de conhecimento, pelas afecções em geral, entre outros.

Encontros que vamos tendo e fazendo durante a vida; de participar, com o outro e consigo, deste movimento de estar vivo. Um processo que avança na medida em que nos reconhecemos no outro - docente-profissional de saúde-aluno-usuário - em um único processo de produção. Produção do quê? De subjetivação, de vida produção do cuidado. Um cuidado que implica a produção de encontros, de conexões existenciais em aberto. Cuidado entre vivos, com suas singularidades e multiplicidades, em acontecimento.

Passamos a vida em encontros, sendo afetados por eles e afetando os outros. Afecções que nos movimentam para a vida, para a produção de um cuidar próprio com mobilização de elementos vitais e, também, outros processos de afecções que 
mobilizam, ao contrário, muito pouco da nossa potência de viver. Encontros que potencializam a vida, no sentido da biopotência, convocando a potência da vida na sua dimensão afetiva, cooperativa, do desejo, da inteligência, em um processo que se atualiza constantemente no contato com o outro. Potência de vida como aquilo que provoca e é provocado pelos encontros ${ }^{13}$.

O cuidado nesta dimensão alarga as possibilidades de escuta, de fala, de gestos, de odores, de observação, de toques, de sabores, de olhares, ou seja, amplia os elementos sensíveis e de pensamento empregados na produção do cuidado. Movimenta e expande, no ato do cuidar, a biopotência do próprio encontro.

Permitir que as multiplicidades do plano do cuidado sejam experimentadas e agenciadas pelos múltiplos sujeitos em produção, remete ao entendimento de que cada sujeito é multidão e que nos constituímos na multiplicidade. A cada instante nos produzimos diferentes, com gestos, quereres, gostos, opinião, um ser distinto daquilo que éramos antes. O experimentar como ingrediente da formação nos desafia, sobremaneira, a construir estratégias pedagógicas que sejam capazes de deixar vazar as multiplicidades dos sujeitos em um coletivo múltiplo, com encontros precários. Precários na sua inconcretude e infinitude, na produção de subjetivação, experimentando no acontecimento ${ }^{14}$.

Deixar vazar as multiplicidades remete a experimentar, não interpretando aquilo que nos afeta, mas desabrochando naquilo que nos afeta. Aquilo que nos toca no olhar, na escuta, costumamos traduzir buscando representar as sensações.

Desabrochar nos afetos coloca a sensação daquilo que nos toca, nos passa em outro lugar, na construção de outros modos de subjetivação presentes na ação do encontro ${ }^{15}$.

Experimentar supõe um agir, um interagir pelo qual o corpo apreende um conteúdo qualquer, isto é, Ihe confere um sentido. Recupera na memória recordações de ações vividas. Um desabrochar nos afetos com o apelo às experiências passadas que se atualizam no ato do produzir-se em formação.

[...] para Bergson, o equilíbrio encontra-se no jogo entre os dois extremos da experiência humana: nem viver na pura ação, reagindo imediatamente como os animais inferiores, nem viver como um sonhador, evocando lembranças sem vínculo com a situação atual. ${ }^{16}$ (p. 30-1)

O jogo do equilíbrio na experiência implica um ato pedagógico que provoque sentido e vínculo sobre a prática do cuidar. Mobiliza afetos e promove novas rotas de agir pedagógico na formação em saúde, a partir da construção de uma caixa de ferramenta ${ }^{(f)}$.

Caixa de ferramenta que remete à produção de estratégias e ferramentas pedagógicas que não sejam rígidas demais nem fluidas em demasia. Na formação como experimentar, o exercício de ensinar ganha outra dimensão, seja na enfermaria, ambulatório, em uma visita domiciliar, enfim, qualquer que seja o plano da experiência no encontro com o outro.

Adentramos nestes espaços com alguma vivência, o que nos remete de imediato à nossa memória, que, no ato, se atualiza diante do dado real. A partir daí, temos uma série, quase que infinita, de caminhos, como: ficar com aquilo que sabemos, pontuando o nosso rígido saber, com pouca margem para experimentar; ampliar um pouco mais com a escuta, abrindo a caixa, mas fechando em seguida com a prescrição de modos de controlar a doença. Podemos, ainda, partir da nossa vivência, incorporando os acontecimentos

\author{
(f) A caixa de ferramentas \\ para Merhy ${ }^{4}$ é composta \\ dos saberes que o \\ trabalhador dispõe para a \\ produção de cuidado em \\ saúde, que, quando \\ utilizada, "maior será a \\ possibilidade de se \\ compreender o problema \\ de saúde enfrentado e \\ maior a capacidade de \\ enfrentá-lo de modo \\ adequado, tanto para o \\ usuário do serviço quanto \\ para a própria \\ composição dos processos \\ de trabalho" (p. 57).
}


presentes na relação que se dá neste ato, desabrochando na incerteza da ação como a única certeza que temos.

A formação como experimentação convoca, no ato, aquilo que nos passa, o que nos acontece, que nos toca quando estamos diante de cenário de aprendizado professor-usuário-profissional-aluno. Convoca-nos a buscar nas experiências anteriores, na memória, desabrochando o sentido da situação vivida. Sentido como conhecimento, como produtor de perguntas que nos lance para outras conexões possíveis de serem identificadas e trabalhadas.

\section{Formação como um movimento de produzir-se}

Formar é estar em formação, é produção, é produzir-se. Tal afirmação implica processos que se tornem imanentes e referentes às multiplicidades do encontro. Ou seja, a partir do encontro, estamos em produção, produção de diferentes formas de ser no mundo, diferentes formas de cuidar de si e do outro.

O ato da formação convoca vários meios, não só o conhecimento racional e lógico. Convida também aquilo que está no entre os sujeitos que participam do processo. Elementos que passam a ser produzidos durante o encontro e que não existam, e incidem no processo pedagógico ou de cuidado e, muitas vezes, não encontram linguagem falada capaz de expressar o seu significado, mas que

${ }^{(g)}$ Clarice Lispector, no seu livro Água Viva ${ }^{18}$, nos mostra que, no plano dos afetos, passam "coisas" que não viram linguagem escrita ou falada, mas se inscrevem no corpo. De modo semelhante, pensadores como Deleuze e Guattari ${ }^{9} \mathrm{e}$ Merhy ${ }^{19}$, de acordo com um certo olhar spinosista, afirmam o mesmo sentido. conferem sentido ao ato(g). Porém, quando se expressam como ideias, adquirem sempre uma dimensão polissêmica, habitadas por sentidos diferentes. É comum ouvir, durante estes encontros, alguém dizer: "Nossa! Nunca havia pensado desta forma. Ah! Agora entendi". Ou seja, durante o ato, estabeleceu-se um processo único e singular que promoveu a produção de algo que passou a fazer sentido e que não havia antes.

Produção de processos de enunciação em disputa por outros modos de formação, com agenciamentos que alargam o formar, agindo na biopotência dos encontros como produção usuário-profissional-professor-aluno. O produzir-se na formação desloca o movimento da dicotomia para a não-dicotomia, nos lança no paradoxo dos encontros e suas variações intensivas, na sua micropolítica. Nessa concepção, a pergunta "o que se produz?" não constitui um produto ao final, mas expande-se em múltiplos processos.

Produção que se faz na dobra dos encontros. Dobra como o ato em que torna possível a produção de subjetivações a partir de uma relação intercessora, consigo mesmo e com outro, em uma produção contínua e no mesmo instante da experimentação, em ato ${ }^{17}$. Nos encontros estamos nos produzindo em movimento de dobra, ou seja, em atos que nos remetem para dentro de nós mesmos, junto e na interação com o outro. Um ato que se estabelece a partir das afecções daquilo que nos passa, o que nos toca, nos impulsiona e nos desloca para dentro e provoca mudanças sobre nossas ações, remetendo-nos a uma produção diferente da que estávamos construindo anteriormente. Produzindo-se em dobras, em instantes e planos de intensa produção subjetiva.

Durante o processo de aprender e ensinar, frequentemente, entramos em situações das quais é difícil reproduzir da mesma forma o que aconteceu. Podemos sair com algo a mais, mas isso não é inevitável. Por exemplo, um grupo de usuários que frequenta um determinado serviço, ao buscar resolver seus problemas relacionados a alguma das doenças crônicas não transmissíveis, se encontra diante de uma oferta feita pelo serviço que, com frequência, é um grupo de educação e saúde. A princípio, um dispositivo tradicional, normatizado, mas que pode ser diferente, pode se transformar em um novo mecanismo de agenciamento coletivo de subjetivação. No espaço do inter aluno-usuário- 
professor-profissional, se discute sobre a vida, como estar na vida. Entra-se no exercício das afecções e não somente de produtos, como a redução da glicemia, mas, também, de constituir-se como modos de viver. Normalmente, nos encontramos diante de provocações de diferentes ordens que só têm sentido durante o processo. Dobramos-nos sobre nós mesmos e sobre os outros, o que significa buscar o sentido daquela experiência, daquilo que nos impulsiona para a vida. Produzir-se na singularidade do coletivo, no cuidar do outro. Agimos no entre nós.

Produzir-se na formação em dobra constitui a experimentação aluno-profissional-docente-usuário, dobrando-se sobre e entre as potencialidades, subjetividades dos encontros que se estabelecem neste processo de formação.

O produzir-se em dobra coloca docentes-alunos-profissionais-usuários como experimentadores de um dentro que dobra e de um fora que desdobra, no interior das relações de poder da vida, em um campo intersubjetivo. Segundo Deleuze ${ }^{20}$ (p. 56), "a desdobra não é o contrário da dobra, mas segue as dobras até outra dobra [...]", em um movimento intenso que tece rotas e caminhos capazes de produzir intensidades com potência de redesenhar o cuidado, a partir da desorganização que provoca na formação, abrindo-se para outros processos, lançando-a para outro plano com outras possibilidades de existência, em um contínuo acontecer.

O movimento do desdobrar-se seguindo até outra dobra, na formação, remete à produção de intercessões entre os sujeitos e a intensividade subjetiva, durante a experimentação pedagógica do agir. Um movimento subjetivante do trabalho vivo em que pode haver outros processos, centrados nas relações, nos encontros sucessivos entre alunos-professores-usuários-profissionais de saúde, em alternativa aos modos cristalizados na lógica da formação como transmissão de saber, enquanto conhecimento racional sistematizado, modos de subjetivação que se estabelecem sobre dobras sólidas constituídas pelo modelo hegemônico no campo da saúde.

No plano da dobra, que desdobra a todo instante, entramos por dentro de processos bem sólidos, como a classificação das doenças que enuncia protocolos e dita formas de como viver. Atravessamos processos que nos passam, nos tocam, nos deslocam e convocam a produção de escuta daquilo que vai além da doença e nos invade com outras formas de produzir saúde e vida. Implicam-nos ética e politicamente. Formas que dão visibilidade aos sujeitos e aos seus modos singulares de estarem e andarem a vida.

Isto é, plano da micropolítica, dos eixos de forças intensivas, que atualizam, nas suas relações de poder, como reproduzimos ou não os modos e formas de dominação do outro e de nós mesmos, de processos intensos abertos nos encontros, dobra e desdobra dos quais precisamos nos apropriar. Há, neste processo, a possível produção das novidades que remetem a sistemas de interações complexas entre alunos-professores-usuários-profissionais de saúde que merecem ser exploradas na prática da formação.

\section{Formação como território do trabalho vivo}

Outro conceito-ferramenta diz respeito à formação na saúde e seu território no mundo do trabalho, pois é exatamente neste plano que os encontros profissional-aluno-docente-usuário são mais micropolíticos e intensos. Sobre território, há estudos no campo do cuidado em saúde que vêm questionando a ideia de que seja algo rígido e geográfico. Na realidade, os usuários que frequentam os serviços de saúde se inserem enquanto território existencial de um modo muito singular no campo das relações sociais, culturais e de vida.

Se observarmos com atenção, tomamos, de um lado, o território geográfico socialmente estabelecido como o bairro, a cidade e o que há de equipamentos institucionais como referência: escolas, creches, supermercados, lanchonetes etc., e delimitamos espaço físico entre ruas, avenidas, rios etc. De outro lado, podemos tomá-los como resultado das articulações entre a sociedade, o movimento nos seus múltiplos aspectos: sociais, econômicos, políticos, culturais e outros. A sociedade está sempre em movimento. A mesma paisagem, a mesma configuração territorial nos oferecem, no transcurso histórico, espaços diferentes ${ }^{21}$. Estes espaços diferentes conformam espacialidades singulares ao território. 
Efetivamente, somos um território existencial que articula e atravessa, durante o movimento de viver, os aspectos subjetivo e cultural. Não nos fixamos no geográfico. No movimento do território existencial, vamos atrás de ofertas que nos façam mais sentido, situadas em outros espaços materiais e imateriais que não o bairro ou lugar de trabalho 22 .

Portanto, o mundo do trabalho é um território marcado pela presença de muitos elementos agenciadores de subjetivações, que, como tais, operam em linhas de forças no campo micropolítico das relações intercessoras, que estão presentes no plano da produção da vida e da existência. Dessa forma, o mundo do trabalho em saúde é plenamente aberto aos acontecimentos e, por isso,

[...] o ato do trabalho funciona como uma escola, ele mexe com a nossa forma de pensar e de agir no mundo. Formamo-nos, basicamente, no trabalho por ser o lugar de produção do agir em saúde, dos profissionais de saúde e dos saberes que são ali produzidos. Esse exercício cotidiano em si é um ato pedagógico. ${ }^{23}$ (p. 198)

O trabalho, funcionando como exercício pedagógico, configura a dimensão da ação do produzir-se, no encontro com o outro. A aproximação do aluno, do docente e do usuário, no mundo do trabalho, ao centro do cuidado, do serviço, dos encontros e dos acontecimentos que teimam em colocar o usuário a vida do outro a dar sentido -, pela sua configuração territorial, no centro de si, nos põem em permanente questionamento do agir sobre o outro, apontando a possibilidade do agir com.

Tomemos, como exemplo deste complexo território, o que acontece em uma enfermaria entre o usuário acamado, o aluno em formação e o professor. Esta cena pode se dar com a prescrição de técnicas, procedimentos voltados para a melhoria das condições de saúde do usuário, que, ao mesmo tempo, exige a aplicação de saberes por parte do aluno e sobre o qual o professor, atento, avalia. Aqui reproduzimos o conhecimento aprendido sobre uma única lógica racional centrada nas evidências dos sinais e sintomas. Há pouca margem às outras lógicas de conhecimento, pois o exercício se produz na busca de evidências externas que encontra ressonância na classificação nosológica.

Esta cena pode se passar de outra forma, mobilizando outros dispositivos durante a aplicação da técnica dura, as tecnologias leves ${ }^{4}$ que nos fazem debruçar sobre o usuário, buscando outros sentidos além da doença para que aquela ação possa se estabelecer, ou seja, haver um produzir-se, alunodocente-usuário. A atitude do aluno se coloca para uma escuta problematizadora, o professor estimula a ação de reflexão sobre a questão ao identificar elementos, dispositivos que sirvam para problematizar a situação, que peçam outros saberes além daqueles cientificamente protocolados. Saberes que estão sendo agenciados no coletivo e que podem incorporar o usuário e seu mundo como centro da cena, outros territórios existenciais. O encontro produz-se daquilo que brota, desabrocha do entre e é atravessado pelo externo. Neste movimento, constitui-se um território de intensidades múltiplas e atravessadas pelas necessidades, desejos dos principais atores que circulam no serviço. Disputas de projetos, de planos de cuidados, de planos e atos pedagógicos que passam a instituir novos territórios e a pedir relações cooperativas pela centralidade da vida no centro dos encontros. Multiplicidades constitutivas do território do trabalho em saúde. "A multiplicidade não deve designar uma combinação de múltiplo e de um, mas, ao contrário, uma organização própria do múltiplo enquanto tal, que não tem necessidade alguma da unidade para formar um sistema"10 (p. 236).

Nesta perspectiva de constituição do território como multiplicidade, há a combinação múltipla de elementos que se fazem presentes no agir pedagógico em produção do trabalho vivo. Trabalho vivo ${ }^{4}$, aquele que, no exato instante da sua ação, interage com normas, máquinas, tecnologias diversas, dobrando e desdobrando-se em fuga, no campo micropolítico.

O ato em saúde se dá em meio à existência efetiva do trabalho vivo em ato, e deste modo implica uma imprevisibilidade que impossibilita, fora do encontro, haver ação. Desse modo, operar sobre o território do trabalho vivo é um espaço aberto à exploração de potências nele inscritas. Abre a perspectiva de ampliar ações pedagógicas com dispositivos que produzam desvios na formação.

Um agir constitutivo das disputas, formas e modos de produzir-se, de atualizar a potência da vida, na potência da formação. Um desafio interessante a ser enfrentado. Extrapolar territórios, criando novidades a partir da multiplicidade do coletivo que se expressa durante o trabalho vivo. 
As disputas no território do trabalho vivo são possíveis de serem evidenciadas quando, por exemplo, os profissionais de saúde (aluno, professor) prescrevem um dado plano de cuidado, com regras bem definidas e pautadas em sinais e sintomas, para o andar da vida do usuário. Com frequência, tais indicações não são cumpridas, sendo atravessadas por outros planos, projetos de vida e cuidado ditados pelos usuários. Logo, o plano ditado não é cumprido. Ora, normalmente, há uma decepção que invade este encontro. O profissional se recente pela sua "inoperância" e o usuário pela incompreensão daquilo que necessita.

Projetos e planos, neste território, são questionados a cada instante. O interessante é incorporar a potência de vida, reconhecer o território existencial do usuário e provocar movimento.

\section{Formação como criação}

A última extremidade da formação que reconhecemos como conceito-ferramenta é a criatividade. Imersos no mundo virtual, a capacidade de imaginar e projetar é tomada ao extremo. Por outro lado, embota a nossa capacidade criativa vinculada ao experimentar. As formas metodológicas de ensinar têm se valido muito pouco do exercício criativo. Na verdade, precisamos inventar um modo diferente de formar que inclua a criatividade.

Inventar, criar é da ordem dos encontros intercessores. Criatividade, na formação, implica estar afinado com outro paradigma que não seja somente o cartesiano, um paradigma que reconheça o real em sua infinita capacidade de combinação de modos de ser, ver e experimentar.

A habilidade de criar pode ser entendida, fundamentalmente, como autocriação a partir de um processo de reconhecimento do outro. Este processo requer, para sua execução, a espontaneidade do movimento da vida ${ }^{24}$.

Se existe um verdadeiro potencial criativo, podemos esperar encontrá-lo em conjunto com a projeção de detalhes introjetados em todos os esforços produtivos, e devemos reconhecer a criatividade potencial não tanto pela originalidade de sua produção, mas pela sensação individual de realidade da experiência [...].24 (p. 130)

Nessa lógica, a criatividade passa a ser relacionada com o estar vivo com os vários encontros produzidos no ato pedagógico. A formação, em seu fazer cotidiano, relaciona-se com o saber inscrito e tatuado na experiência do trabalho. Neste jogo, no entre, a espontaneidade, o gesto espontâneo durante $o$ ato vivo do produzir-se, revela as formas criativas de ensinar, aprender.

\section{Considerações finais}

A utilização de conceitos-ferramentas refere-se a colocar, no foco das discussões da formação em saúde, as várias intenções e implicações dos atores envolvidos na micropolítica do ensino e do cuidado. Tomar os conceitos com a finalidade de constituir a matéria-prima para a produção de conversa e redes coletivas de contato entre os trabalhadores, usuários, alunos, professores, é explorar a potência que se desenha no fazer produtivo com os atos pedagógicos.

O potencial criativo exercido no trabalho vivo da formação em saúde representa um território que não coloque a doença como ingrediente principal do cuidar, mas amplie a nossa capacidade de construção de outros elementos com potencialidade para invadir outros territórios. Representa o sair em busca de experimentar novos territórios existenciais; experiências de formação que se projetam sobre territórios que mobilizem o contato com outras culturas, com outros modos de existência, a partir do trabalho vivo, como agir pedagógico.

É a ferramenta operando com capacidade de provocar rupturas, arranhões nas dobras rígidas e cristalizadas do agir pedagógico que se centra sobre uma única verdade. 


\section{Colaboradores}

Os autores trabalharam juntos, construindo todas as etapas de produção do texto.

\section{Referências}

1.Bondía JL. Notas sobre a experiência e o saber de experiência. Rev Bras Educ. 2002; (19):20-8.

2. Lana LCC, França RO. Do cotidiano ao acontecimento, do acontecimento ao cotidiano. Rev Assoc Nac Prog Pos-Grad Comunic. 2008; 11(3):1-13.

3. Deleuze G. Lógica do sentido. São Paulo: Perspectiva; 1982.

4. Merhy EE. Saúde: a cartografia do trabalho vivo. São Paulo: Hucitec; 2002.

5. Guattari F, Rolnik S. Micropolítica: cartografias do desejo. Petrópolis: Vozes; 2000.

6. Ceccim RB. Educação permanente em saúde: descentralização e disseminação de capacidade pedagógica na saúde. Cienc Saude Colet. 2005; 10(4):975-86.

7. Abrahão AL, Teixeira ER. Aspectos metodológicos do estudo transdisciplinar e da psicossomática no cuidado com o corpo. In: Teixeira ER, organizador. Psicossomática no cuidado em saúde: atitude transdisciplinar. São Caetano do Sul: Yendis; 2009. p. 69-89.

8. Guattari F. Revolução molecular: pulsações políticas do desejo. 3a ed. São Paulo: Brasiliense; 1987.

9. Deleuze G, Guattari F. O que é filosofia? São Paulo: Ed. 34; 1982.

10. Deleuze G. Diferença e repetição. Rio de Janeiro: Graal; 2006.

11. Merhy EE, Franco TB. Por uma composição técnica do trabalho em saúde centrada no campo relacional e nas tecnologias leves. Apontando mudanças para os modelos tecnoassistenciais. Saude em Debate. 2003; 27(65):316-23.

12. Foucault M. A hermenêutica do sujeito. São Paulo: Martins Fontes; 2010.

13. Pelbart PP. Vida capital: ensaios de biopolítica. São Paulo: Iluminuras; 2003.

14. Deleuze G. Espinosa: Filosofia prática. São Paulo: Escuta; 2002.

15. Rolnik S. Micropolíticas em atrito [audiovisual]. São Paulo: Instituto CPFL Cultura; 2009 [acesso 2012 Out 27]. Disponível em: http://www.cpflcultura.com.br/site/2009/ 10/16/integra-micropoliticas-em-atrito-suely-rolnik

16. Menéndez JG. A relação entre percepção e memória: aproximações e divergências entre Freud e Bergson. AdVerbum. 2006; 1(1):23-34.

17. Merhy EE. O ato de cuidar: a alma dos serviços de saúde. In: Ministério da Saúde. Secretaria de Gestão do Trabalho e Educação na Saúde. Departamento de Gestão da Educação na Saúde. Ver-SUS Brasil: caderno de textos. Brasília: Ministério da Saúde; 2004. p. 108-37.

18. Lispector C. Água Viva. Rio de Janeiro: Rocco; 1998.

19. Merhy EE. O mais profundo é a pele. Interface (Botucatu). 2011; 15(38):915-17.

20. Deleuze G. A dobra: Leibniz e o Barroco. São Paulo: Papirus; 2007.

21. Santos M. A natureza do espaço: técnica e tempo, razão e emoção. São Paulo: Hucitec; 1996.

22. Campos GWS, Chakour M, Santos RC. Análise crítica sobre especialidades médicas e estratégias para integrá-las no SUS. Cad Saude Publica. 1997; 13(1):141-5. 
FORMAÇÃO EM SAÚDE E MICROPOLÍTICA: ...

23. Merhy EE. Engravidando as palavras: o caso da integralidade. In: Pinheiro R, Mattos $R$, organizadores. Construção social da demanda. Rio de Janeiro: IMS-UERJ, Abrasco; 2005. p. 195-206.

24. Winnicott DW. O brincar e a realidade. Rio de Janeiro: Imago; 1975.

Abrahão AL, Merhy EE. Formación en salud y micro-política: sobre conceptos-herramientas en la práctica de enseñar. Interface (Botucatu). 2014; 18(49):313-24.

Los cambios en la formación en salud en las últimas décadas han formado parte de la agenda de la política del Estado brasileño en el campo metodológico y pedagógico, con propuestas de reestructuración de los currículos y una mayor aproximación a los servicios. La formación en el campo de la salud se trabaja en este artículo a partir de algunos conceptos-herramientas, articulados con cuatro tensiones presentes en este campo: formación como movimiento de producirse; formación como territorio del trabajo vivo; formación como experimentar y formación como creación. El propósito de este estudio es ponderar las tensiones presentadas a partir de los encuentros teóricos, alineados a la producción de herramientas conceptuales con potencia para instalar nuevos modos de ejercicio en la formación en salud. El análisis señala el potencialcreativo, ejercido en lo micro-político en el acto de la formación. Como elemento principal amplía la experiencia y la capacidad de ver otros ingredientes y otros territorios en la actuación pedagógica.

Palabras clave: Enseñanza. Micro-política. Formación en salud.

Recebido em 20/05/13. Aprovado em 21/11/13 